\title{
Lessons from Blending Electrospraying for Cultivating the Students' Ability of Resolving Complicated Engineering Problems
}

\author{
Xin-Kuan Liu*, Xin-Yi Lu, Yuan Hou, Kai Cui, Dengguang Yu \\ School of Materials Science and Engineering, University of Shanghai for Science and Technology, \\ 516 Jungong Road, Shanghai 200093, China. \\ Email: xinkuanliu@163.com \\ *Corresponding author
}

\begin{abstract}
The ability of solving complicated engineering problem is very important for undergraduate students who major in materials science and engineering and want to become excellent engineers. However, how to train them and develop their problem-solving ability poses a big challenge for their teachers. The key is to choose suitable teaching materials, which should be full of interesting but complex engineering problems. In this paper, an advanced nanotechnology-blending electrospraying is explored as a model. A series of complicated engineering problems are refined by implementing a whole electrospray process, which includes the preparation of working fluids, optimization of experimental parameters, systematic characterization of electrospray nanoparticles, and potential commercial applications. These problems not only act as the effective teaching materials to promote students to master this advanced nanotechnology, but also are developed to cultivate their capability of resolving complicated engineering problems. This means that one thing will kill two birds with one stone. This paper shows innovative ways for the applications of advanced technologies in engineering teaching in higher education.
\end{abstract}

Keywords-Engineering education; Blending electrospraying; Complex engineering problems; Undergraduate student

\section{BACKGROUND}

Today, more and more attention has been drawn on the cultivation of undergraduate students' capability of resolving complicated engineering problems, which should be a basic quality of them in future when they become an excellent engineer in the society. However, in China, the students often lack enough opportunities to be trained how to put forward a complicated engineering problem and how to resolve it all by themselves in their campus. When they go to work after graduation, they often need a relatively long time period to train their engineering ability, suggesting a step late than the anticipation.

In the university, often their teachers are busy with their scientific researches, in which advanced technologies can be met here and there. It is a pity that these advanced techniques are only exploited in experimental laboratory. They can be excellent teaching materials for training the students' capability of understanding and resolving complicated engineering problems. Particularly in the disciplines related with materials science and engineering, large-scale industrial production is only a magnified version of the experimental process in the scientific laboratory. This is to say that small as the sparrow is, it possesses all its internal organs for the laboratory material experiment.

An experiment about "Electrosprayed drug-loaded nanoparticles" is just an example for exhibiting the teaching strategy. Shown in Fig. 1 is a diagram about the whole procedure of a laboratory scientific experiment for creating electrosprayed drug-loaded nanoparticles using an advanced nanotechnology--blending electrospraying [1-4]. Apparently, the procedure includes several interrelated steps, i.e. (1) the preparation of suitable working fluid, (2) the reasonable process with the optimized experimental parameters, (3) the systematic characterization of the resulted nanoparticles, and (4) the potential commercial applications. Within each step, a series of complicated engineering problems can be refined from them, which can be utilized for both teaching the advanced technology to the college students and training their capability of thinking and resolving complicated engineering issues. 


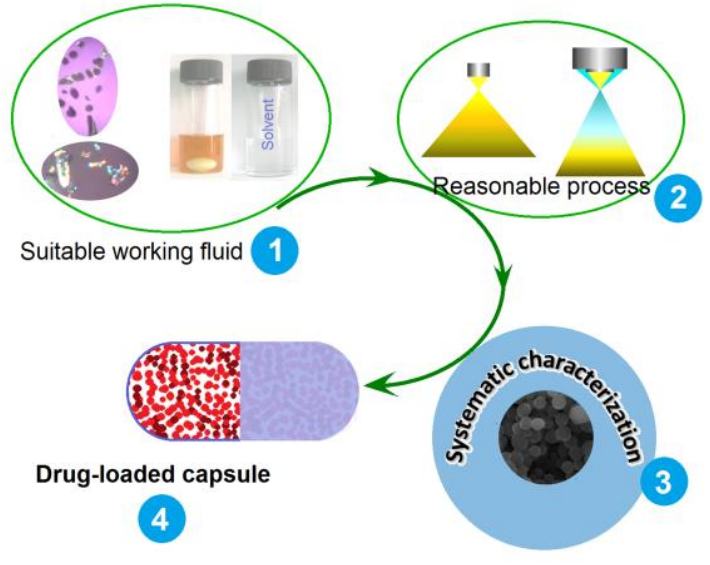

Fig. 1 A diagram about the whole procedure of a laboratory scientific experiment with an advanced nanotechnology-blending electrospraying as a model, this procedure includes (1) the preparation of suitable working fluid, (2) the reasonable process with the optimized experimental parameters, (3) the systematic characterization of the resulted nanoparticles, and (4) the potential commercial applications.

\section{COMPlicAted EngineERING PROBlem DURING THE PREPARATION OF WORKING FLUID}

Both electrospraying and electrospinning belong to electrohydrodynamic atomization processes, in which electrostatic energy is exploited to treat the working fluids [59]. Often, solid nanoparticles or nanofibers are expected to be created after the treating processes [10-13]. However, the working fluids utilized in the electrospraying processes are totally different with those exploited in the electrospinning processes. Before the experiment about "Electrosprayed drugloaded nanoparticles" is carried out, the first thing is the preparation of drug-loaded working solution. Needless to say, the solution must contain active ingredient, drug carrier and also their co-dissolving solvent or solvent mixture (Fig. 2). This is a complicated engineering problem whose resolution needs to consider a series of mutual constraints. For example, in the selection of solvent for preparing working fluid, solvent with a high boiling point (such as $\mathrm{N}, \mathrm{N}$-dimethylacetamide (DMAc), who has a high boiling point of $168^{\circ} \mathrm{C}$ ) is favorable for reducing the final solid nanoparticles' size, but it may make the electrospraying a failure because it is very difficult to be evaporated during the electrospraying processes. The solvent with a low boiling point (such as dichloromethane, who has a high boiling point of $38{ }^{\circ} \mathrm{C}$ ) is favorable for solidification of the working fluid, but it may also make the electrospraying a failure because it is easy to clog the nozzle of spray head due to the formation of semi-solid substance [14-17]. No matter high or low boiling points the solvents have, they should have a good solubility of both the active ingredients and also the drug carriers. This determines that the drug and carrier can form a co-dissolving solution for being treated using the blending electrospraying process.

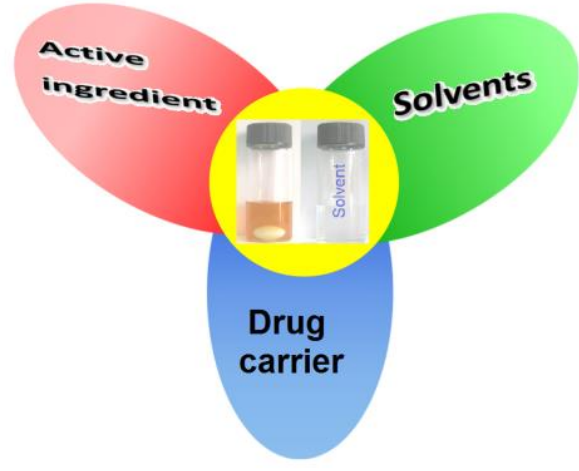

Fig. 2 The convergent point of a series of factors needed to be considered for the preparation of working fluid for implementing the blending electrospraying processes.

\section{COMPLICATED ENGINEERING PROBLEM REFINED FROM THE OPTIMIZATION OF THE EXPERIMENTAL PARAMETERS}

Certainly, based on the concept of "electro-hydrodynamic", the electrical and hydrodynamic properties of the working fluids are very important. Thus, the formation of a co-dissolved solution as working fluid is only the first step. The most important factor is that the preparation of working fluid should also take the following factors into consideration, such as conductivity, viscosity, and also surface tension [1821]. Meanwhile, these parameters of working fluid have a close relationship with the experimental conditions (Fig. 3). The association study of working fluid's properties and the operational parameters comprises a complicated engineering problem. On one hand, the solution of this kind of complicated problem often needs to be considered in a comprehensive way. On the other hand, the solution of the problem should be beneficial to the increase of students' engineering creative ability.

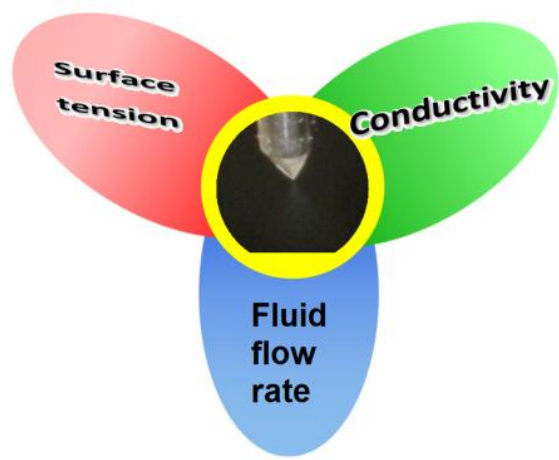

Fig. 3 A typical complicated engineering problem about the systematic optimization of experimental parameters for implementing the blending electrospraying processes.

Among all the experimental parameters, the fluid low rate is one of the most important parameters in the electrohydrodynamic processes [22-25]. Besides it has a close relationship with the properties of the working fluid, the matchings between it and applied high voltage, between it and nozzle-to-collector particle accepted distance are also 
complicated problems. For example, a large fluid flow rate may need a higher applied voltage and a smaller particle accepted distance for achieving solid nanoparticles with high quality. The solution of this kind of complicated problem should increase the students' engineering practice abilities, endow them more powerful in resolving complicated engineering issues encountered in their future job.

\section{COMPLICATED ENGINEERING PROBLEM CAN BE DRAWN FROM THE SYSTEMATIC CHARACTERIZATION OF THE ELECTROSPRAYED NANOPARTICLES}

The education about advanced technologies comprises one of the most important tasks in high school, which can effectively serve as the foundation for engineering education. For materials science and engineering discipline, the advanced technologies can be divided into two categories [26-28]. One is for fabrication of advanced materials. And the other is for characterization of all kind unknown functional materials. Complicated engineering problems exist in both the fabrication processes and also the characterization processes. However, their patterns of manifestation are different. The former has a joint point, i.e. the generation of high quality nanoparticles, which requests all the considerations should center around this goal. And thus, the resolution of related complicated engineering problems is easy to be evaluated. In sharp contract, the later often comprises a series of parallel methods, which determines that the evaluation of measurement has no unified standard. However, these different characterization methods can be organized together to provide an evaluation closer to the objective fact. Correspondingly, the solution of this kind of complicated problem should increase the students' comprehensive tradeoff ability abilities, endow them more powerful in resolving complicated engineering issues in a systematic manner.

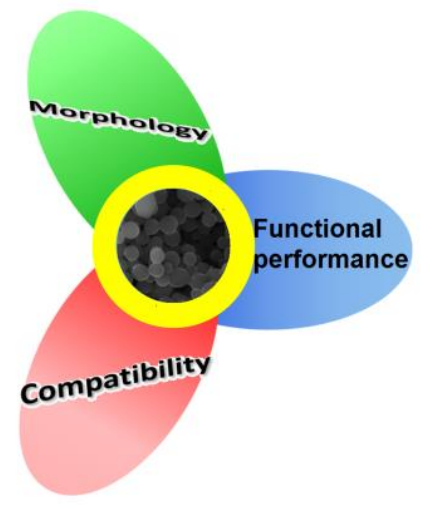

Fig. 4 Some complicated engineering problems can be drawn from the systematic characterization of the electrosprayed solid nanoparticles.

For example, for characterization of the electrosprayed drug-loaded nanoparticles (Fig. 4), a series of properties and also functional performances of the nanoparticles should be considered systematically. As nano-scale products, the sizes and morphologies should be analyzed using the modern instruments, such as scanning electron microscope, transmission electron microscope, atomic force microscope and so on. As a drug-loaded nanoproducts, the compatibility between the drug and the carrier should be investigated using instruments such as Fourier Transform infrared spectroscopy, Raman spectroscopy, and X-ray diffraction. Certainly, as a functional materials, the functional performances of the electrosprayed nanoparticles should be evaluated in details, such as in vitro dissolution tests, ex vivo permeation tests. These systematic characterizations should provide an objective evaluations on the quality of resultant electrosprayed nanoparticles.

\section{COMPLICATED ENGINEERING PROBLEM RELATED WITH THE POTENTIAL COMMERCIAL APPLICATIONS}

The complicated engineering issues never exist in a separate manner within the engineering field. Being aimed to possible commercial applications, these medicated nanoparticles should have a series of complicated engineering problems that have a close relationship with the social factors and the patients. As an intermediate dosage form, these electrosprayed nanoparticles need to be transferred into final commercial products, such as tablet or capsule (Fig. 5). Then, a complicated engineering problem occurs, i.e. how to integrate the advanced electrospraying with the traditional pharmaceutical technologies (such as tableting and encapsulation methods). The resolution of this kind of engineering problems needs professional experiences on both materials engineering and also pharmaceutics, which should be useful to broaden the ken of college students. Certainly, the complex engineering problems also include those have a close relationship with the issues of economic, environment and sustainable development.

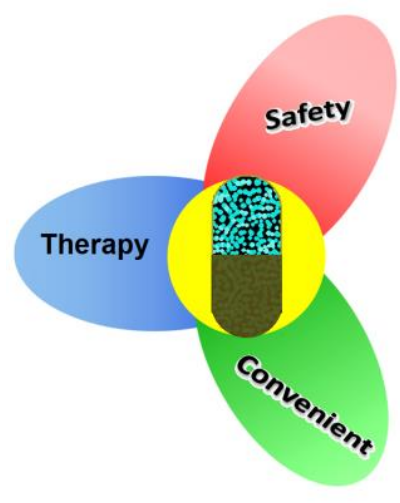

Fig. 5 There are some complicated engineering problems related with the the potential commercial applications of the electrosprayed drug-loaded nanoparticles. 


\section{SUMMARY}

In the present job, blending electrospraying is explored as an advanced nanotechnology model to explain how to cultivate the students' ability of resolving complicated engineering problems. During the implementation of blending electrospraying processes, there are often many complicated engineering problems that need to be solved. These problems, on one hand, are very useful for the college students to deepen the knowledge about this advanced nanotechnology. And on the other hand, these problems are also excellent teaching materials for training the students' ability of resolving complicated engineering problems.

\section{ACKNOWLEDGMENT}

The financial supports from the following projects are appreciated: the Shanghai Education Science Research Project (C17058), the National Natural Science Foundation of China (No. 51373101), the 2017 Graduate curriculum reform project in USST, and the College Student Innovation Project of USST (Nos.SH2018).

\section{REFERENCES}

[1] B. Sanchez-Vazquez, A.J. Amaral, D.G. Yu, G. Pasparakis, and G.R. Williams, "Electrosprayed Janus particles for combined photochemotherapy," AAPS PharmSciTech, vol.8, pp.1460-1468, 2017.

[2] Z.P. Liu, L.L. Zhang, Y.Y. Yang, D. Wu,G. Jiang, and D.G. Yu, "Preparing composite nanoparticles for immediate drug release by modifying electrohydrodynamic interfaces during electrospraying," Powd. Technol., vol.327, pp.179-187, 2018.

[3] K. Wang, H.F. Wen, D.G. Yu, Y. Yang, and D.F. Zhang, "Electrosprayed hydrophilic nanocomposites coated with shellac for colon-specific delayed drug delivery," Mater. Design, vol.143, pp.248 255, 2018.

[4] Y.Y. Yang, M. Zhang, Z.P. Liu, K. Wang, and D.G. Yu, "Meletin sustained-release gliadin nanoparticles prepared via solvent surface modification on blending electrospraying," App. Surf. Sci., vol.434, pp.1040-1047, 2018.

[5] Z.P. Liu, Y.Y. Zhang, D.G. Yu, D. Wu, and H.L. Li, "Fabrication of sustained-release zein nanoparticles via modified coaxial electrospraying,” Chem. Eng. J., vol.334, pp.807-816, 2018.

[6] D.G. Yu, C. Yang, M. Jin, G.R. Williams, H. Zou, X. Wang, et al, "Medicated Janus fibers fabricated using a Teflon-coated side-by-side spinneret," Colloid. Surface B, vol.138, pp.110-116, Feburary 2016.

[7] Y.H. Wu, D.G. Yu, H.P. Li, X.Y. Wu, and X.Y. Li, "Medicated structural PVP/PEG composites fabricated using coaxial electrospinning," e-Polymers, vol.17, pp.39-44, January 2017.

[8] Q. Wang, H.P. Li, C. Yang, J.J. Li, and D.G. Yu, "Beads-on-a-string amorphous solid dispersion fabricated using a modified coaxial electrospinning," J. Control. Release, vol.259, pp.e111-e112, 2017.

[9] J.J. Li, Chen Yang, Hai-Peng Li, Qing Wang, and Deng-Guang Yu, "Oral controlled release in accordance with drug adsorption biological rhythm provided by an electrospun structural amorphous solid dispersion," J. Control. Release, vol.259, pp.e61-e62, 2017.

[10] X.Y. Li, Z.B. Zheng, D.G. Yu, X.K. Liu, Y.L. Qu, and H.L. Li, "Electrosprayed sperical ethylcellulose nanoparticles for an improved sustained-release profile of anticancer drug," Cellulose, vol.24, pp.55515564, 2017.
[11] D.G. Yu, H.P. Li, C. Yang, J.J. Li, Q. Wang, and G.R. Williams, "Double-pulsatile release core-shell fibers fabricated using modified triaxial electrospinning," J. Control. Release, vol.259, pp.e24-e25, 2017.

[12] C. Yang, D.G. Yu, D. Pan, X.K. Liu, X. Wang, S.W.A. Bligh, et al, "Electrospun $\mathrm{pH}$-sensitive core-shell polymer nanocomposites fabricated using a tri-axial processes," Acta Biomater., vol.35, pp.77-86, April 2016.

[13] X. Liu, W. Shao, M. Luo, J. Bian, D.G. Yu, "Electrospun blank nanocoating for improved sustained release profiles from medicated gliadin nanofibers," Nanomaterials, vol.8, Article ID 184 (11 pages), 2018.

[14] Y.H. Wu, D.G. Yu, J.J. Li, Q. Wang, H.P. Li, and X.Y. Li, "Medicated multiple-component polymeric nanocomposites fabricated using electrospraying," Polym. Polym. Compos. vol.25, pp.57-62, 2017.

[15] Q. Wang, D.G. Yu, S.Y. Zhou, C. Li, and M. Zhao, "Fabrication of amorphous electrospun medicated-nanocomposites using a Teflon-based concentric spinneret," e-Polymer, vol.18, pp.3-11, 2018.

[16] Z. Zhang, W. Li, G. Wang, Y.L. Qu, and D.G. Yu, "Electrospun 4th generation solid dispersions of poorly water-soluble drug utilizing two different processes,” J. Nanomater. Vol.2018, Article ID 2012140, 2018.

[17] H.F. Wen, C. Yang, D.G. Yu, X.Y. Li, and D.F. Zhang, "Electrospun zein nanoribbons for treatment of lead-contained wastewater," Chem. Eng. J., vol.290, pp.263-272, April 2016.

[18] G.Z. Yang, H.P. Li, J.H. Yang, J. Wan, and D.G. Yu, "Influence of working temperature on the formation of electrospun polymer nanofibers," Nanoscale Res. Lett., vol.12, Article 15, January 2017.

[19] Y.H. WU, H.P. Li, X.X. Shi, J. Wan, Y.F. Liu, and D.G. Yu, "Effective utilization of the electrostatic repulsion for improved alignment of electrospun nanofibers," J. Nanomater., vol.2016, Article ID2067383, 2016.

[20] Y.Y. Yang, Z.P. Liu, D.G. Yu, K. Wang, P. Liu, X. Chen, "Colonspecific pulsatile drug release provided by electrospun shellac nanocoating on hydrophilic amorphous composites," Int. J. Nanomed., vol.2018, DOI: 10.2147/IJN.S154849, 2018

[21] M. Jin, D.G. Yu, X. Wang, C.F.G.C. Geraldes, G.R. Williams, and S.W.A. Bligh, "Electrospun contrast agent-loaded fibers for colontargeted MRI," Adv. Healthcare Mater., vol.5, pp.977-985, April 2016.

[22] Q. Wang, D.G. Yu, L.L. Zhang, X.K. Liu, Y.C. Deng, and M. Zhao, "Electrospun hypromellose-based hydrophilic composites for rapid dissolution of poorly water-soluble drug," Carbohydr. Polym., vol.174, pp.617-625, Oct, 2017.

[23] Y.H. WU, C. Yang, X.Y. Li, J.Y. Zhu, and D.G. Yu, "Medicated nanofibers fabricated using $\mathrm{NaCl}$ solutions as shell fluids in a modified coaxial electrospinning," J. Nanomater., vol.2016, Article ID 8970213, 2016.

[24] D.G. Yu, J.J. Li, M. Zhang, and G.R. Williams, "High-quality Janus nanofibers prepared using three-fluid electrospinning," Chem. Commun. vol.53, pp.4542-4545, April 2017.

[25] G.Z. Yang, J.J. Li, D.G. Yu, M.F. He, J.H. Yang, and G.R. Williams, "Nanosized sustained-release drug depots fabricated using modified triaxial electrospinning," Acta Biomater., vol.53, pp.233-241, April 2017.

[26] K. Wang, X.K. Liu, X.H. Chen, D.G. Yu, Y.Y. Yang, and P. Liu, "Electrospun hydrophilic Janus nanocomposites for the rapid onset of therapeutic action of helicid," ACS Appl. Mater. Interfaces, vol.10, pp.2859-2867, 2018.

[27] M. Jin, D.G. Yu, C.F.G.C. Geraldes, G.R. Williams, and S.W.A. Bligh, "Theranostic fibers for simultaneous imaging and drug delivery," Mol. Pharm., vol.13, pp.2457-2465, July 2016.

[28] Y. Xu, J.J. Li, D.G. Yu, G.R. Williams, J.H. Yang, and X. Wang, "Influence of the drug distribution in electrospun gliadin fibers on drugrelease behavior,” Eur. J. Pharm. Sci., vol.106, pp.422-430, August 2017. 